Brazilian Journal

of Chemical

ISSN 0104-6632

Engineering

Printed in Brazil

Vol. 21, No. 02 pp. 275 - 284, April - June 2004

\title{
A STUDY OF A WIRE-PLATE ELECTROSTATIC PRECIPITATOR OPERATING IN THE REMOVAL OF POLYDISPERSED PARTICLES
}

\author{
S. W. Nóbrega ${ }^{1}$, M. C. R. Falaguasta ${ }^{2}$ and J. R. Coury ${ }^{2 *}$ \\ ${ }^{1}$ Departamento de Engenharia Química, Universidade Federal de Alagoas, \\ Phone +(55) (82) 214-1280, Fax +(55) (82) 214-1625, Campus A. C. Simões, \\ BR 104, km 14, 57072-970, Maceió - AL, Brazil. \\ E-mail: swn@ctec.ufal.br \\ ${ }^{2}$ Departamento de Engenharia Química, Universidade Federal de São Carlos, \\ Phone +(55) (16) 260-8264, Fax +(55) (16) 260-8266, Rodovia Washington \\ Luís, km 235, Cx. P. 676, CEP 13560-970, São Carlos - SP, Brazil. \\ E-mail: jcoury@power.ufscar.br
}

(Received: February 13, 2003 ; Accepted: October 7, 2003)

\begin{abstract}
Performance of a wire-plate electrostatic precipitator in the removal of particles with a wide particle size distribution was evaluated. The experimental rig utilized consisted of a set of three precipitators whose dimensions could be varied. It was observed that precipitator performance increased with an increase in the gap between the collecting plates, which resulted in a substantial increase in energy consumption per volume of cleaned gas. The grade efficiency predicted by correlations from the literature did not match the experimental measurements, and a new correlation is proposed.

Keywords: electrostatic precipitator, gas cleaning, particle collection.
\end{abstract}

\section{INTRODUCTION}

The electrostatic precipitator is widely employed in the control of particles emissions in different industrial processes. In this equipment, the particles in the gaseous current are electrically charged and separated from the gas under the influence of an electric field.

Project and operation parameters have a big influence on the performance of a precipitator. Although a great deal of research has been done on the influence of these parameters, contradictory conclusions are often reported.

The shape of the precipitator has considerable influence on its performance. Many researchers (e.g. Leonard et al., 1980; Petersen, 1981; Riehle and Löffler, 1992a) discuss this influence, but the conclusions are contradictory. Chang and Bai (2000) used a mathematical model to show that the wider precipitators do not function as well. Navarrete et al. (1997), however, verified that precipitators with wider ducts were more efficient in the removal of high resistivity materials.

The performance of electrostatic precipitators is, in general, evaluated under different electric operational conditions, which is perhaps what leads to the different conclusions observed in the literature. The complexity of the phenomenon is poorly addressed in the models available for predicting collection efficiency, particularly in the submicron particle size range.

The objective of this work was to study the performance of the electrostatic precipitator in the removal of a particulate with a wide range of sizes, under different operational conditions and to compare the results for collection efficiency with predictions by available theoretical models.

*To whom correspondence should be addressed 


\section{Collection Efficiency}

In the literature there are several correlations for prediction of collection efficiency in electrostatic precipitators. However, their use has been limited by empirical constants that are difficult to estimate as well by their complexity in some cases (Zhao and Pfeffer, 1996).

The classic model for collection efficiency, known as the Deutsch equation, Equation 1, is still frequently used to predict the performance of precipitators due to its simplicity (Riehle, 1997). In this model it is assumed that the profile for concentration of particles in any traverse section of the duct is uniform.

$\eta_{\text {dpi }}=1-e^{\left(\frac{-w_{\text {th }} \mathrm{A}}{Q}\right)}=1-e^{\left(\frac{-\mathrm{w}_{\text {th }} \mathrm{L}_{\mathrm{NE}}}{\mathrm{v}_{\mathrm{o}} \mathrm{s}}\right)}$

In this equation, $\mathrm{w}_{\text {th }}$ is the theoretical migration velocity, which is obtained from the use of balance equations on a particle, assuming Stokes law, and is given by

$\mathrm{w}_{\mathrm{th}}=\frac{\mathrm{Q}_{\mathrm{p}}^{\infty} \mathrm{ECu}}{3 \pi \mu \mathrm{d}_{\mathrm{p}}}$

To calculate migration velocity, Riehle (1997) suggests using the Cochet equation (Equation 3 ) for estimation of the saturation charge of the particles, $\mathrm{Q}_{\mathrm{p}}{ }^{\infty}$. The electric field, still according to Riehle, can be estimated by the ratio of applied potential to the distance of the wire from the plate (s).

$\mathrm{Q}_{\mathrm{p}}^{\infty}=\left[\left(1+\frac{2 \lambda}{\mathrm{d}_{\mathrm{p}}}\right)^{2}+\left(\frac{2}{1+\frac{2 \lambda}{\mathrm{d}_{\mathrm{p}}}}\right)\left(\frac{\varepsilon_{\mathrm{r}}-1}{\varepsilon_{\mathrm{r}}+2}\right)\right] \pi \varepsilon_{\mathrm{o}} \mathrm{d}_{\mathrm{p}}^{2} \mathrm{E}$

Attempting to avoid the assumption of a constant concentration profile in the Deutsch model, several other researchers suggested new models that consider the diffusivity of the particle in the flowing gas.

Zhibin and Guoquan (1994) included the effect of diffusion in their development of an analytic model for collection efficiency in which the equation of bidimensional transport of the particles as a function of concentration (Equation 4) was analytically solved. Equation 5 gives the solution presented by the authors.

$\mathrm{D}_{\mathrm{p}} \frac{\partial^{2} \mathrm{C}}{\partial \mathrm{y}^{2}}-\mathrm{v}_{\mathrm{o}} \frac{\partial \mathrm{C}}{\partial \mathrm{x}}=\mathrm{w}_{\mathrm{th}} \frac{\partial \mathrm{C}}{\partial \mathrm{y}}$

$$
C(x, y)=\frac{C_{0} b \sqrt{v}}{2 \sqrt{\pi D_{p} x}} \exp \left(X^{\prime}\right)
$$

with

$X^{\prime}=-\frac{v\left(y-\frac{w x}{v}\right)^{2}}{4 D_{p} x}$

where $\mathrm{y}$ and $\mathrm{x}$ are the axial and traverse distances in respect to the gas flow, respectively.

From the definition of collection efficiency, it follows that

$\eta_{\text {dpi }}=1-\left(\frac{P e}{4 \pi \mathrm{De}}\right)^{0.5} \int_{0}^{1} \mathrm{e}^{\left(\frac{-\mathrm{Pe}(\xi-\mathrm{De})^{2}}{4 \mathrm{De}}\right)} \mathrm{d} \xi$

where the Pèclet, Pe, and Deutsche, De, numbers are given by

$\mathrm{Pe}=\frac{\mathrm{w}_{\mathrm{th}} \cdot \mathrm{s}}{\mathrm{D}_{\mathrm{p}}}$

$\mathrm{De}=\frac{\mathrm{w}_{\mathrm{th}} \cdot \mathrm{L}_{\mathrm{NE}}}{\mathrm{v}_{\mathrm{o}} \cdot \mathrm{s}}$

Equation 7 is therefore the theoretical model of Zhibin and Guoquan (1994) for collection efficiency in electrostatic precipitators.

\section{MATERIALS AND METHODS}

\section{Experimental Setup}

The experimental system used in this study consisted of three electrostatic precipitators of the wire-plate type, whose main dimensions are given in Table 1. A schematic view of one of the three modules is shown in Figure 1.

Each precipitator consisted of a rectangular box built of acrylic and PVC, with the lateral walls covered by grounded copper plates. These plates constituted the collection electrodes. The discharge electrodes were stainless steel wires, stretched halfway and orthogonal between the collecting plates. The distance between the electrodes (2c) could be varied for each precipitator, according to the values presented in Table 1. 
Table 1: Main dimensions of the precipitators utilized.

\begin{tabular}{|r|c|c|c|}
\hline & \multicolumn{3}{|c|}{ Precipitator } \\
\cline { 2 - 4 } & $\mathbf{0 1}$ & $\mathbf{0 2}$ & $\mathbf{0 3}$ \\
\hline $2 \mathrm{~s}(\mathrm{~cm})$ & 10 & 15 & 20 \\
$2 \mathrm{c}(\mathrm{cm})$ & $3.3 ; 5.0 ; 10.0$ & $5.0 ; 7.5 ; 15.0$ & $6.6 ; 10.0 ; 20.0$ \\
$2 \mathrm{r}_{\mathrm{SE}}(\mathrm{mm})$ & 0.5 & 0.5 & 0.5 \\
$\mathrm{~L}_{\mathrm{NE}}(\mathrm{cm})$ & 60 & 60 & 60 \\
$\mathrm{~h}_{\mathrm{NE}}(\mathrm{cm})$ & 30 & 30 & 30 \\
\hline
\end{tabular}

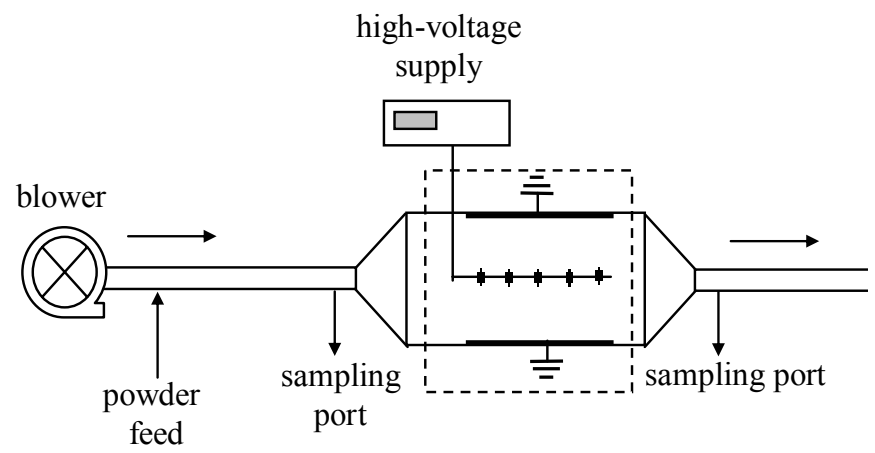

(a)

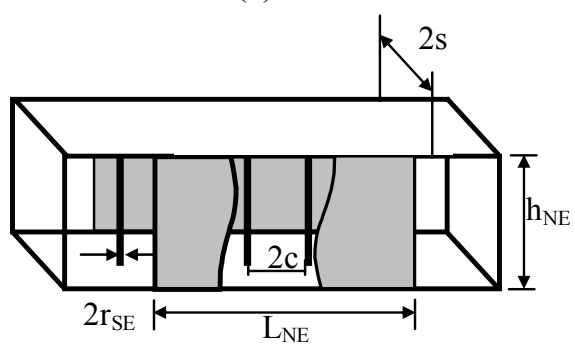

(b)

Figure 1: (a) Scheme of a module of the experimental unit; (b) Shape of the precipitator

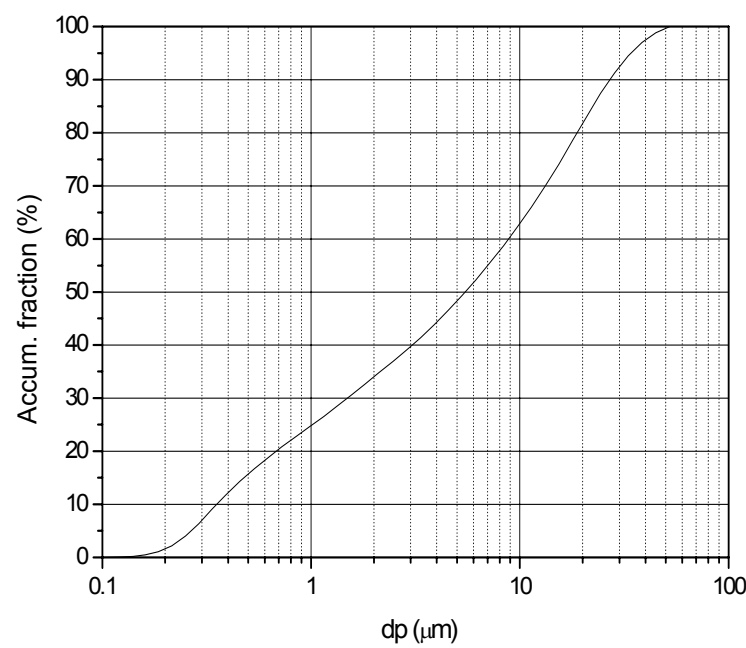

Figure 2: Size distribution of the particulate matter utilized. 


\section{Particulate}

The particulate material used in the experimental tests was a phosphatic concentrate with an electric resistivity of $8.3 \cdot 10^{8} \mathrm{Wm}$, a dielectric constant of 6.5 and a density of $3.0 \cdot 10^{3} \mathrm{~kg} / \mathrm{m}^{3}$. The size analysis of this powder was obtained utilizing an equipment, the Malvern Mastersizer, which determines the particle size distribution by laser diffraction. The size distribution of the powder utilized in this work is shown in Figure 2.

\section{Experimental Tests}

The methodology used in the tests consisted in initially setting up the experimental system with the levels of the variables to be tested: the blower was started and the air flow rate adjusted so that the gas velocity inside the precipitator reached the required value.

The test was then started with the feeding of the particulate matter. After reaching the steady state (approximately five minutes), the powder concentration was measured at the entrance of the system by isokinetic sampling. Soon after, a new sampling was taken as the matter left the precipitator to obtain the concentration of particles at the exit of the system.

The grade efficiency of collection $\left(\eta_{\mathrm{dpi}}\right)$ for each test was obtained from the size analysis of the particulate matter retained in the filters used in the samplings. The particulate matter sampled from the precipitator was re-dispersed in a solution (deionized water plus dispersant agent) utilizing an ultrasonic bath. The suspension was then put in a Malvern Mastersizer, where size was analyzed.

From the results obtained in these analyses, together with the particle concentrations at the entrance and exit of the system, grade efficiency was calculated with the use of the following equation

$\eta_{\text {dpi }}(\%)=\left(1-\frac{c_{S} \Delta d_{p i}^{S}}{c_{E} \Delta d_{p i}^{E}}\right) 100$

\section{RESULTS AND DISCUSSION}

\section{Influence of Duct Width on Precipitator Performance}

Figure 3 shows the experimental results of the performance of two precipitators with different widths $2 \mathrm{~s}$, operating with the same specific collection area (A/Q), for three values of applied electric field. All the curves show an identical behavior: efficiency reaches a minimum in the vicinity of the $1 \mu \mathrm{m}$ size range. Efficiency in the removal of larger particles is well understood and the electric force created by the precipitator is reliably correlated with removal forces. Some comprehensive reviews on the subject can be found in the literature (Oglesby and Nichols, 1978; Parker, 1997). Conversely, efficiency in the submicron range does not have a clear theoretical description and is still poorly understood. In this size range, the effects of turbulent diffusion and of discontinuity of the flowing medium can prevail.

Figure 3 also shows that an increase in the width of the duct increased particles removal, especially for the electric field of low intensity. The fact that wider precipitators function better is known as the "nonDeutschian" phenomenon (Chang and Bai, 2000). Riehle and Löffler (1992b) attribute this behavior to the fact that the electric field increases in proximity to the collection plates with the increase in the width of the duct, intensifying the collection of particles.

Although the results show that wider precipitators function better, it is important to observe that the costs of installation and operation for these precipitators are higher than those for narrower ducts. This is because the increased width of the duct requires a proportional increase in the electric potential to maintain the same electric field. Consequently, it is necessary to utilize a high-voltage source of larger capacity, increasing the initial cost of installation. Regarding the cost of operation, the power consumed by unit of flow rate of treated gas increases with the width of the duct, as can be observed in Figure 4, where the values in percentage represent the increase in consumption of electricity. Therefore, an increase in the width of the duct might not be economically viable, especially when the specific collection area $(\mathrm{A} / \mathrm{Q})$ is small.

Another form of evaluating the influence of distance between the collection plates (2s) is by comparing precipitator performance for different duct widths with the same consumption of electricity power per unit of treated gas flow rate. The results obtained in these tests are presented in Figure 5. Observing the behavior of these curves, it can be observed that for the same amount of power consumed, performance of the precipitators improves as the distance between the plates decreases. This is due to the fact that the increase in duct width requires more energy to increase the migration velocity of the particles in order to compensate for the increase in the distance to be traveled. 

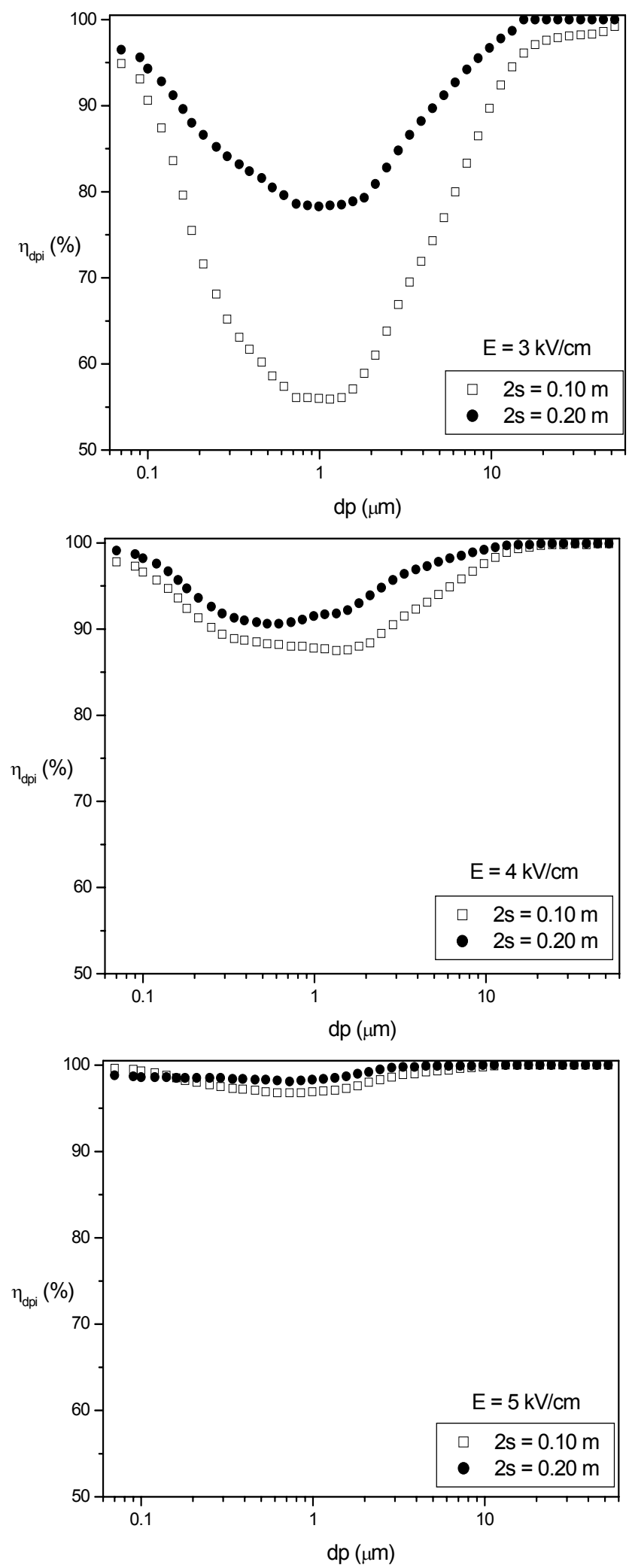

Figure 3: Influence of $2 \mathrm{~s}$ on collection efficiency: $A / Q=12 \mathrm{~s} / \mathrm{m} ; \mathrm{s} / 2 \mathrm{c}=0.5$ 


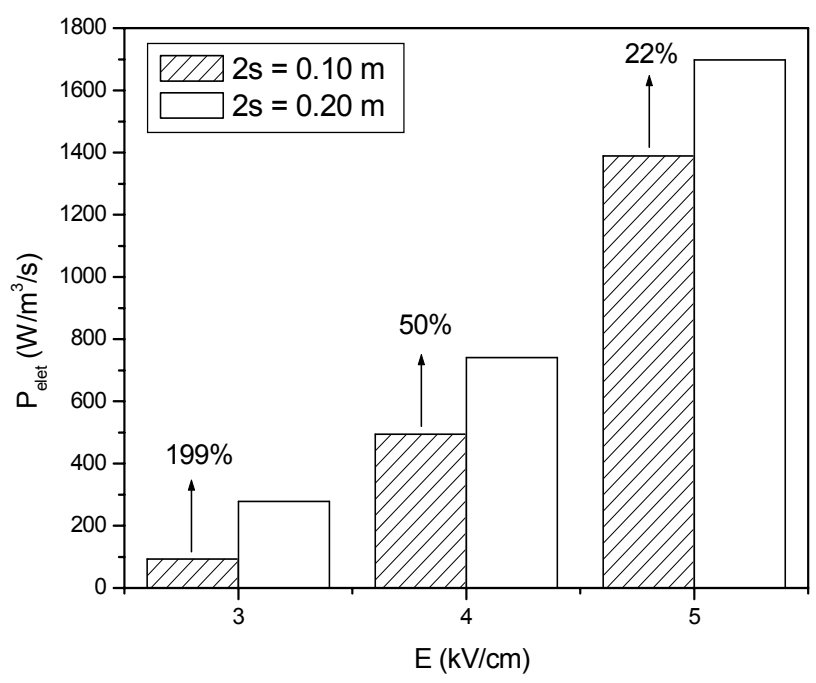

Figure 4: Power consumption per unit of gas flow rate: $A / Q=12 \mathrm{~s} / \mathrm{m} ; \mathrm{S} / 2 \mathrm{c}=0.5$.
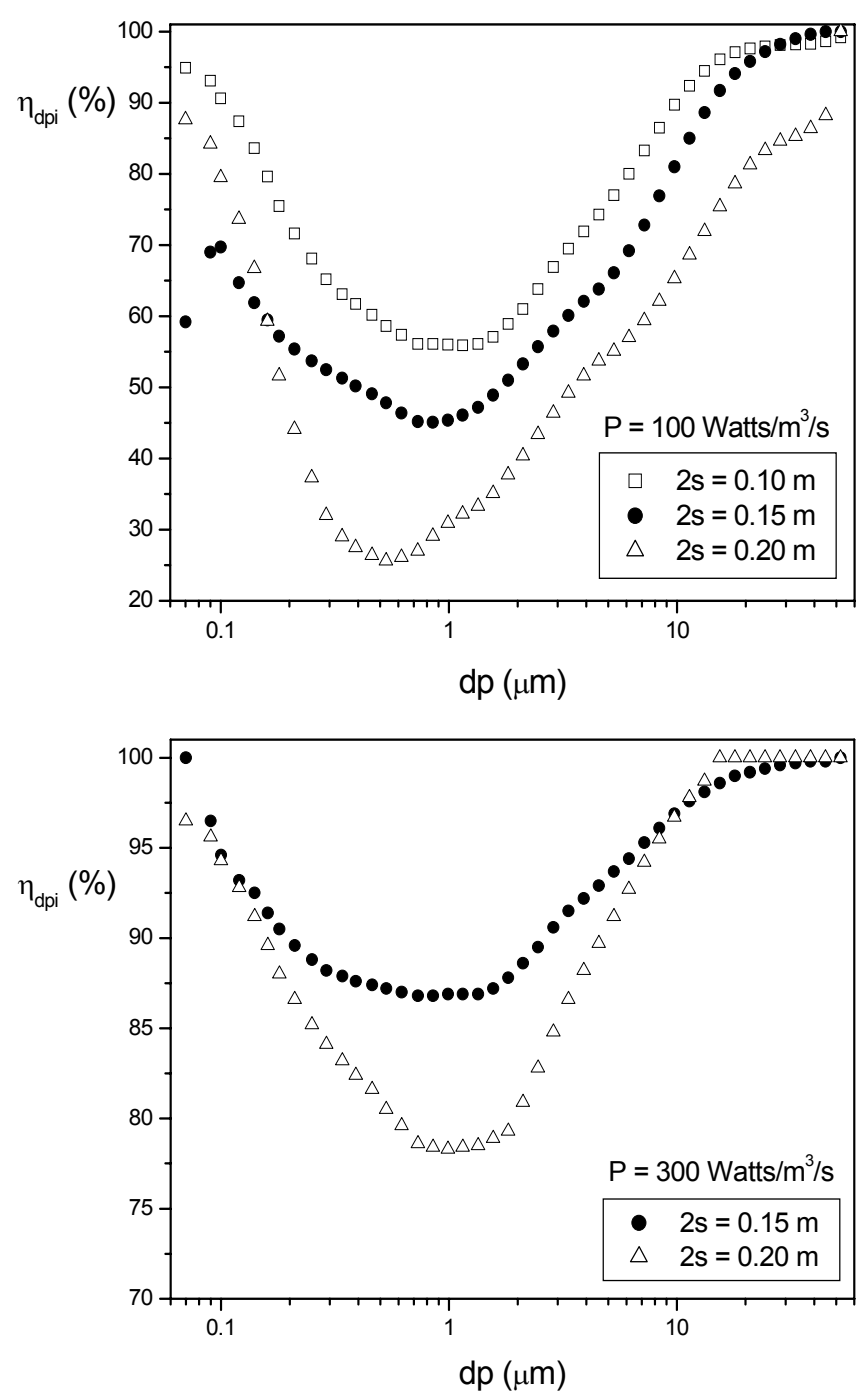

Figure 5: Influence of the distance between the plates on efficiency for precipitators with the same power consumption per unit of gas flow rate. 
Therefore, analyzing the influence of duct width (2s) on the performance of the precipitator, it becomes evident that an increase in this parameter generally causes a higher energy consumption without, however, resulting in a significant improvement in precipitator performance.

\section{Comparison Between Theoretical Models and Experimental Data on Grade Collection Efficiency}

Figure 6 compares values for grade collection efficiency, obtained experimentally with predictions by the models of Deutsch and Zhibin and Guoquan, Equations 1 and 7, respectively. As can be seen in these figures, those correlations did not represent well the experimental data.

An alternative proposal to the solution given by Zhibin and Guoquan is shown in Equation 11, which is also a solution to Equation 4. In this new equation, it is assumed that the concentration of particles is smaller at the center of the precipitator duct and increases moving towards the collection plates, which seems quite reasonably in agreement with the experimental data obtained by Schmid and Umhauer (1998) and shown in Figure 7. Riehle and Löffler (1993) also depicted this behavior in a number of photographs taken from inside a wire-plate precipitator.

$$
\mathrm{C}(\mathrm{x}, \mathrm{y})=\frac{\mathrm{v}^{1.5} \mathrm{yC}_{\mathrm{o}} \mathrm{b}}{\mathrm{wx} \sqrt{\pi \mathrm{D}_{\mathrm{p}} \mathrm{x}}} \exp \left(\mathrm{X}^{\prime}\right)
$$

where $\mathrm{X}^{\prime}$ is given by Equation 6 .

The equation for collection efficiency is given in this case by

$$
\left.\eta_{\text {dpi }}=1-\frac{\sqrt{\frac{P e}{\pi}}}{D e^{1.5}} \int_{0}^{1} \xi \mathrm{e}^{\left[-\frac{P e}{4 D e}(\xi-D e)^{2}\right.}\right] d \xi
$$
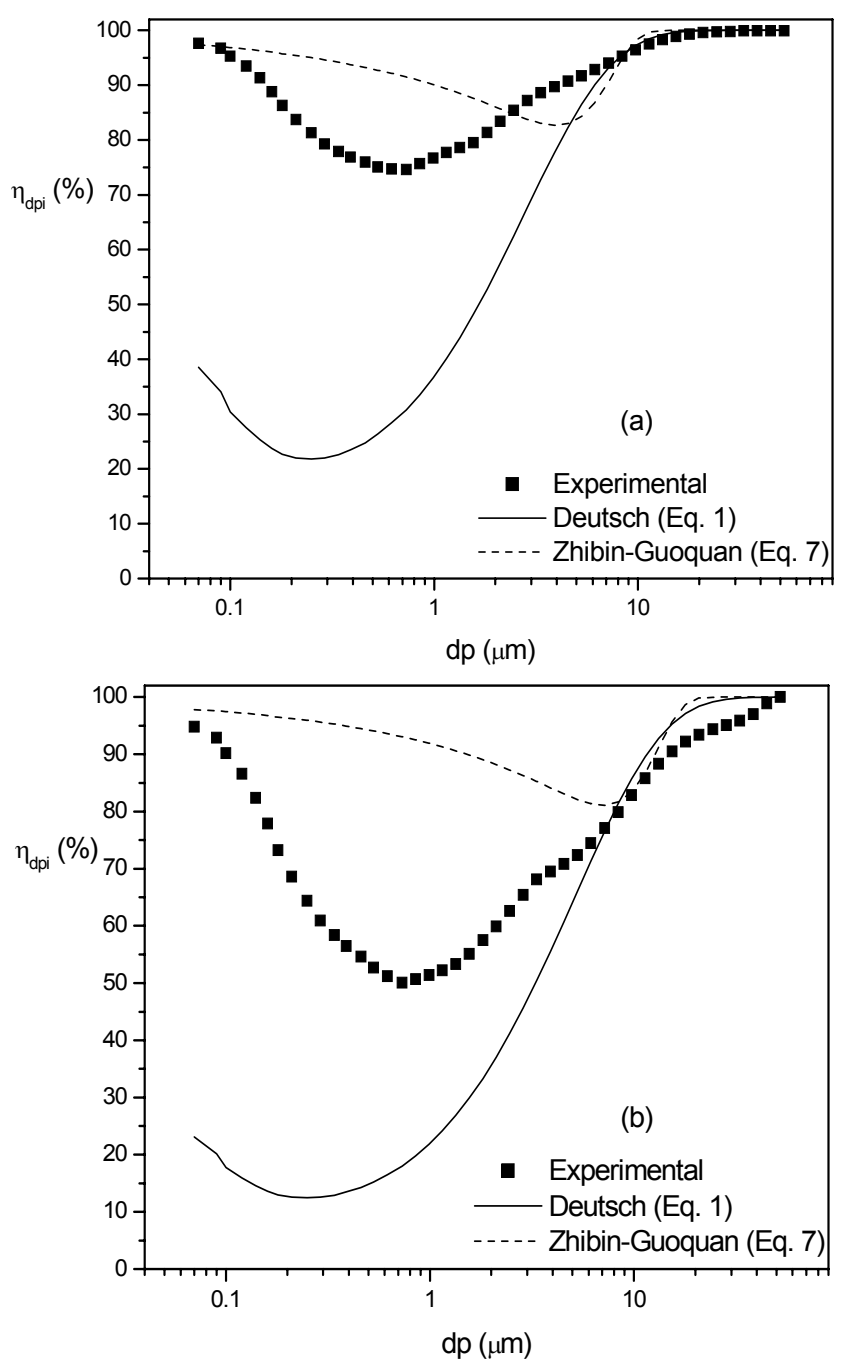

Figure 6: Comparison between theoretical models and experimental data for collection efficiency $2 \mathrm{~s}=0.20 ; \mathrm{s} / 2 \mathrm{c}=1$ (a) $\mathrm{v}_{\mathrm{o}}=1.5 \mathrm{~m} / \mathrm{s}$ and $\mathrm{E}=5 \mathrm{kV} / \mathrm{cm} ;$ (b) $\mathrm{v}_{\mathrm{o}}=1.0 \mathrm{~m} / \mathrm{s}$ and $\mathrm{E}=3 \mathrm{kV} / \mathrm{cm}$. 


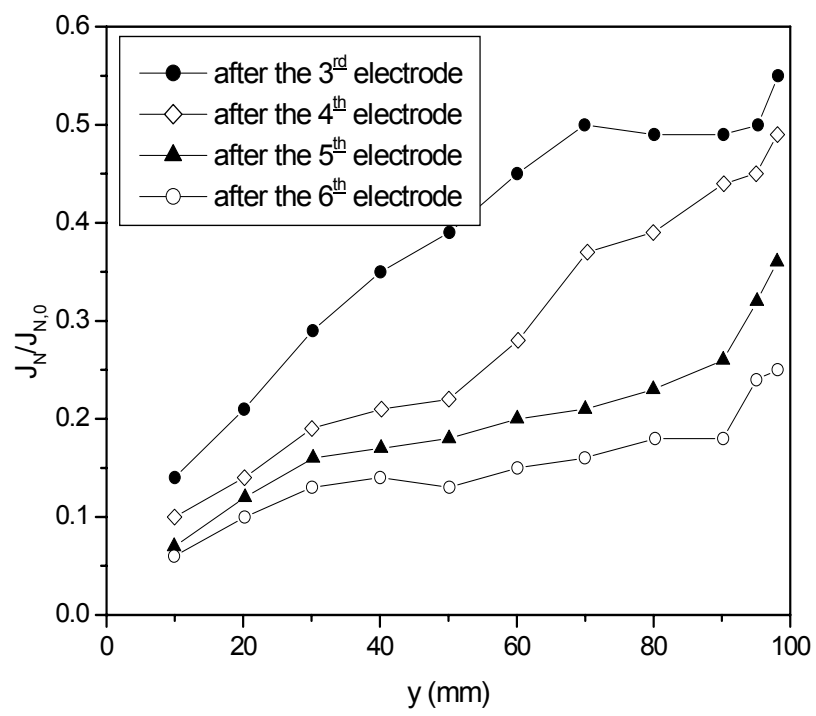

Figure 7: Profile of particle flow in consecutive crossections of the precipitator for $\mathrm{V}=-45 \mathrm{kV}$, $\mathrm{v}_{\mathrm{o}}=1.0 \mathrm{~m} / \mathrm{s}, \mathrm{d}_{\mathrm{p}}=1.0 \mu \mathrm{m}, 2 \mathrm{~s}=0.2 \mathrm{~m}$, from Schmid and Umhauer (1998)

The value to be attributed to the diffusion coefficient, $\mathrm{D}_{\mathrm{p}}$, was a matter of concern. No reliable theoretical correlation is currently available and the one used by Zhibin and Guoquan (1994), in which $D_{p}$ was independent of particle size, did not seem reasonable. For simplicity, $D_{p}$ was assumed to be inversely proportional to particle size, and the proportionality constant was obtain from the experiment. The resulting expression is shown in Equation 13. The values obtained for the range of particle diameters between 0.1 and $10 \mu \mathrm{m}$ varied between 0.01 and 3 $\mathrm{m}^{2} / \mathrm{s}$, which according to Cooperman apud Licht
(1988), is in agreement with the tendencies observed.

$$
\mathrm{D}_{\mathrm{p}}=\frac{2 \times 10^{-7}}{\mathrm{~d}_{\mathrm{p}}}\left(\mathrm{m}^{2} / \mathrm{s}\right)
$$

for $\mathrm{d}_{\mathrm{p}}$ in meters.

A comparison between experimental results and the new correlation (Equation 12) in presented in Figures 8,9 and 10. It can be observed that the model represents the experimental behavior well, responding satisfactorily to the changes in the operational conditions and precipitator shape.

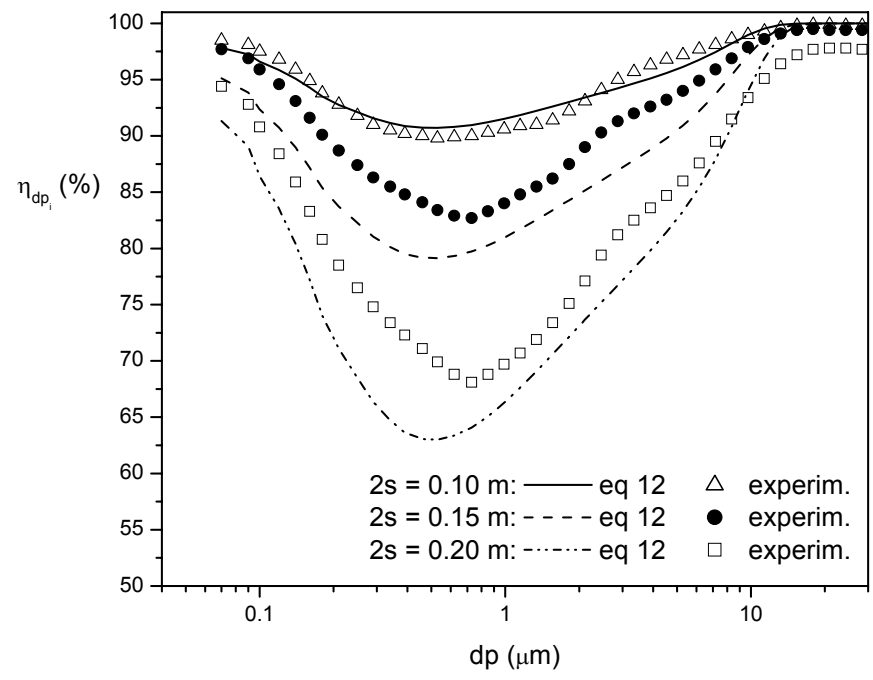

Figure 8: Comparison between theoretical prediction (Equation 12) and experimental data for grade collection efficiency. $\mathrm{E}=4 \mathrm{kV} / \mathrm{cm}, \mathrm{v}_{\mathrm{o}}=1.5 \mathrm{~m} / \mathrm{s}$ and $\mathrm{s} / 2 \mathrm{c}=1.0$. 


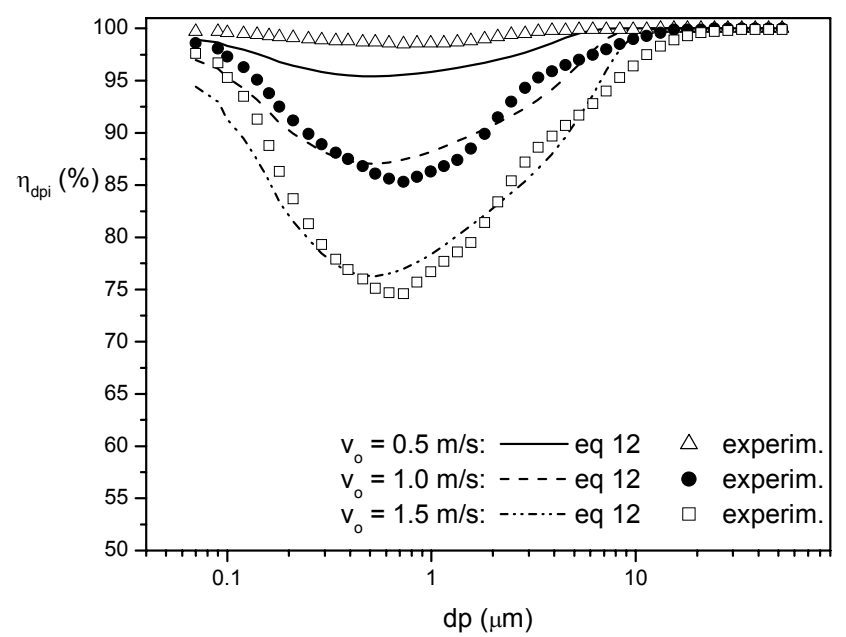

Figure 9: Comparison between theoretical prediction (Equation 12) and experimental data for grade collection efficiency. $\mathrm{E}=5 \mathrm{kV} / \mathrm{cm}, 2 \mathrm{~s}=0.2 \mathrm{~m}$ and $\mathrm{s} / 2 \mathrm{c}=1.0$.

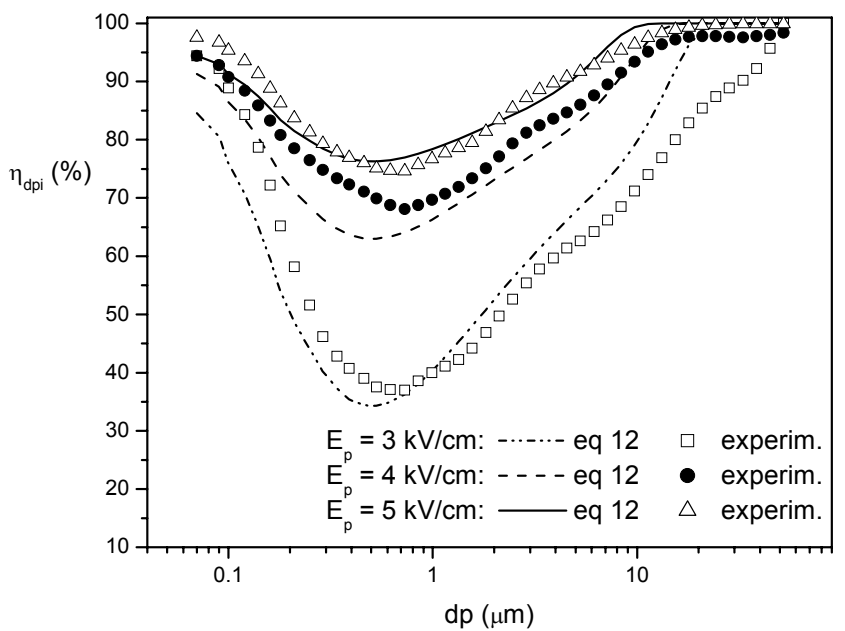

Figure 10: Comparison between theoretical prediction (Equation 12) and experimental data for grade collection efficiency. $\mathrm{v}_{\mathrm{o}}=1.5 \mathrm{~m} / \mathrm{s}, 2 \mathrm{~s}=0.2 \mathrm{~m}$ and $\mathrm{s} / 2 \mathrm{c}=1.0$.

\section{CONCLUSIONS}

The experimental evidence presented here in has shown that an increase in duct width (2s) resulted in an increase in collection efficiency, but also in a larger consumption of energy.

The models of Deutsch and Zhibin and Guoquan (1994) did not predict precipitator efficiency in the submicron particle size range. A new correlation (Equation 12), which represented the experimental behavior very well for different operational conditions, is proposed.

\section{NOMENCLATURE}

A Total collecting area, $\mathrm{m}^{2}$

2c Distance between two discharge electrodes, $m$

$c_{e}$ Mass concentration of particles at the entrance, $\mathrm{kg} / \mathrm{m}^{3}$

$\mathrm{c}_{\mathrm{s}} \quad$ Mass concentration of particles at the exit, $\mathrm{kg} / \mathrm{m}^{3}$

$\mathrm{Cu}$ Cunningham slip correction factor, dimensionless

De Deutsch number, dimensionless 
$\mathrm{d}_{\mathrm{p}} \quad$ Particle diameter, $\mathrm{m}$

$\mathrm{D}_{\mathrm{p}} \quad$ Particle diffusivity, $\mathrm{m}^{2} / \mathrm{s}$

E Electric field, V/m

$\mathrm{L}_{\mathrm{NE}} \quad$ Length of the collecting plate, $\mathrm{m}$

$\mathrm{Pe} \quad$ Pèclet number, dimensionless

Q Gas volumetric flow rate, $\mathrm{m}^{3} / \mathrm{s}$

$\mathrm{Q}_{\mathrm{p}}^{\infty} \quad$ Particle saturation charge, $\mathrm{C}$

$\mathrm{s}$ Distance between the discharge and collecting electrodes, $\mathrm{m}$

2s Duct width, $m$

$\mathrm{v}_{\mathrm{o}} \quad$ Gas velocity, $\mathrm{m} / \mathrm{s}$

$\mathrm{w}_{\text {th }} \quad$ Migration velocity, $\mathrm{m} / \mathrm{s}$

$\Delta \mathrm{d}_{\mathrm{pi}}{ }^{\mathrm{E}} \quad$ Fraction of particles with diameter $\mathrm{d}_{\mathrm{pi}}$ at the entrance of the system, $\%$

$\Delta \mathrm{d}_{\mathrm{pi}}{ }^{\mathrm{S}} \quad$ Fraction of particles with diameter $\mathrm{d}_{\mathrm{pi}}$ at the exit of the system, $\%$

$\varepsilon_{0} \quad$ Permittivity of the vacuum, $8.86 \cdot 10^{-12} \times 10^{-12}$ $\mathrm{As} / \mathrm{Vm}$

$\varepsilon_{\mathrm{r}}$ Dielectric constant of the particles, dimensionless

$\eta_{\text {dpi }} \quad$ Grade efficiency, \%

$\lambda \quad$ Mean free path of the ions, $m$

$\mu \quad$ Gas viscosity, $\mathrm{Ns} / \mathrm{m}^{2}$

\section{ACKNOWLEDGEMENTS}

The authors would like to thank CAPES and PRONEX-FINEP for the financial support that made this work possible.

\section{REFERENCES}

Chang, C.L. and Bai, H., Effects of Some Geometric Parameters on the Electrostatic Precipitator Efficiency at Different Operation Indexes, Aerosol Science and Technology, vol. 33, pp. 228-238 (2000).

Leonard, G. and Mitchner, M., Self, S.A, Particle Transport in Electrostatic Precipitators, Atmospheric Environment, vol. 14, pp.1289-1299 (1980).

Licht, W., Air Pollution Control Engineering - Basic Calculations for Particulate Collection, $2^{\text {nd }}$ Ed.,
Marcel Dekker, New York (1988).

Navarrete, B. and Cañadas, L., Cortés, V., Salvador, L., Galindo, J., Influence of Plate Spacing and Ash Resistivity on the Efficiency of Electrostatic Precipitators, Journal of Electrostatics, vol. 39, pp. 65-81 (1997).

Oglesby, S. and Nichols, G.B., Electrostatic Precipitation, Pollution Engineering and Technology, Marcel Dekker, New York, NY (1978).

Parker, K.R., Applied Electrostatic Precipitation, Blackie Academic \& Professional, New York, NY (1997).

Petersen, H.H., New Trends in Electrostatic Precipitation: Wide Duct Spacing, Precharging, Pulse Energization, IEEE Transactions on Industry Applications, vol. IA-17, no. 5, pp. 496501 (1981).

Riehle, C., Basic and Theoretical Operation of ESPs. In: Parker, K.R., ed., Applied Electrostatic Precipitation, Chap.3, pp. 25-88, Blackie Academic \& Professional, New York, NY (1997).

Riehle, C. and Löffler, F., Electrical Similarity Concerning Particle Transport in Electrostatic Precipitators, Journal of Electrostatics, vol. 29, pp. 147-165 (1992a).

Riehle, C. and Löffler, F., The Effective Migration Rate in Electrostatic Precipitators, Aerosol Science and Technology, vol. 16, pp. 1-14 (1992b).

Riehle, C. and Löffler, F., Reflections on Similarity Laws Concerning Particle Transport in Electrical Precipitators, Powder Technology, vol. 77, pp. 201-208 (1993).

Schmid, H.J. and Umhauer, H., In-situ Measurement of Local Particle Fluxes in a Laboratory-scaled ESP. 7th. International Conference on Electrostatic Precipitation, 20-25 September, Kyongju, Korea (1998).

Zhao, Z.M. and Pfeffer, R., A Semi-empirical Approach to Predict the Total Collection Efficiency of Electrostatic Precipitators, Chemical Engineering Communications, vol. 148-150, pp. 315-331 (1996).

Zhibin, Z. and Guoquan, Z., Investigations of the Collection Efficiency of an Electrostatic Precipitation with Turbulent Effects, Aerosol Science and Technology, vol. 20, pp. 169-176 (1994). 